\title{
Aberrant Neural Responses to Cold Pressor Challenges in Congenital Central Hypoventilation Syndrome
}

\author{
PAUL M. MACEY, KATHERINE E. MACEY, MARY A. WOO, THOMAS G. KEENS, AND \\ RONALD M. HARPER \\ Department of Neurobiology [P.M.M., K.E.M., R.M.H.], University of California at Los Angeles, \\ Los Angeles, California 90095; School of Nursing [M.A.W.], University of California at Los Angeles, \\ Los Angeles, California 90095; Childrens Hospital Los Angeles [T.G.K.], Los Angeles, California 90027; \\ and the Brain Research Institute [R.M.H.], University of California at Los Angeles, Los Angeles, \\ California 90095
}

\begin{tabular}{|c|c|}
\hline \multicolumn{2}{|c|}{ ABSTRACT } \\
\hline $\begin{array}{l}\text { Patients with congenital central hypoventilation syndrome } \\
\text { (CCHS), a condition characterized by impaired ventilatory re- } \\
\text { sponses to chemoreceptor stimulation, do not show the normal } \\
\text { increase in respiratory rate and respiratory-related heart rate } \\
\text { variation to cold forehead stimulation, a challenge that bypasses } \\
\text { central chemoreceptors. We hypothesized that a forehead cold } \\
\text { pressor challenge would reveal abnormal neural response pat- } \\
\text { terns, as assessed by functional magnetic resonance imaging, in } \\
\text { brain regions that are responsible for the integration of cold } \\
\text { afferent stimulation with respiratory and cardiovascular output in } \\
\text { patients with CCHS. Primary sensory thalamic and cortical areas } \\
\text { for the forehead showed diminished responses in } 13 \text { patients with } \\
\text { CCHS (ventilator dependent during sleep but not waking, no } \\
\text { Hirschsprung's disease) compared with } 14 \text { control subjects, de- } \\
\text { spite initial signal changes in the cortex being similar in both } \\
\text { groups. Cerebellar cortex and deep nuclei; basal ganglia; and } \\
\text { middle to posterior cingulate, insular, frontal, and temporal } \\
\text { cortices showed reduced signal rises in patients with CCHS. } \\
\text { Areas within the frontal and anterior cingulate cortices exhibited } \\
\text { marked signal declines in control subjects but little change in }\end{array}$ & $\begin{array}{l}\text { patients with CCHS. No response occurred in either group in the } \\
\text { dorsal medulla, but medial and ventral medullary areas showed } \\
\text { enhanced signals in patients with CCHS. The cold pressor stim- } \\
\text { ulation did not recruit dorsal medullary sites that would be } \\
\text { affected by PHOX2B (a mutation of which is associated with the } \\
\text { syndrome) expression in either group but demonstrated deficient } \\
\text { cerebellar and medial medullary influences that, by action on } \\
\text { rostral sites, may underlie the loss of respiratory responses. } \\
\text { (Pediatr Res 57: 500-509, 2005) }\end{array}$ \\
\hline
\end{tabular}

Congenital central hypoventilation syndrome (CCHS) is characterized by multiple respiratory deficiencies, including diminished drive to breathe during sleep (1) and reduced ventilatory responsiveness to hypercapnia (2-4). Affected individuals do not alter respiratory rate to a forehead cold pressor challenge and show diminished respiratory-related heart rate variation to that stimulation (5); reduced respiratory/heart rate

Received April 28, 2004; accepted September 10, 2004.

Correspondence: Ronald M. Harper, Ph.D., Department of Neurobiology, University of California at Los Angeles, Los Angeles, CA 90095-1763; e-mail: rharper@ucla.edu.

This research was supported by the National Institute of Child Health and Human Development Grant HD-22695.

DOI: 10.1203/01.PDR.0000155757.98389.53 coupling is also found in baseline and sleep conditions (6). The cold pressor findings suggest a nonchemoreceptor respiratory reflex deficit in the syndrome, the trigeminally mediated dive reflex, and indicate failure of integration of respiratory motor output with afferent input. A portion of that failure could stem from autonomic/respiratory interaction deficits, and these deficits may partially derive from maldevelopment of neural visceral areas (e.g. dorsal medullary sites) as a result of mutations of the PHOX2B gene, found in a high proportion of patients with CCHS $(7,8)$. Both chemoreceptor and cold stimuli perception are at least partially intact in CCHS, because affected children arouse from sleep to high $\mathrm{CO}_{2}$ (9) and have perception of forehead cooling. Because the nucleus of the 
solitary tract (NTS) plays a significant role in both chemoreception and temperature mediation (10), damage to this dorsal medullary structure, as well as its afferent processes, must be incomplete in CCHS, yet ventilation to chemoreceptor challenges is seriously impaired. Voluntary and exercise-related respiratory efforts in CCHS are largely preserved (11-13), suggesting that integration of afferent activity with respiratory motor output, rather than a primary chemoreceptor defect, is involved. A ventilatory challenge that did not include chemoreceptor components would be useful to investigate this possibility.

The cold pressor challenge is a means to examine deficient integrative respiratory mechanisms and cardiovascular responses in CCHS, bypassing input from the principal autonomic ganglia that may be affected in the syndrome. The challenge can be administered rapidly, exerts a profound effect on respiratory and cardiovascular patterning, and is noninvasive. We hypothesized that neural responses to a forehead cold pressor challenge, as assessed by functional magnetic resonance imaging (fMRI), would show abnormal patterns in regions that are responsible for the integration of cold afferent stimulation with respiratory and cardiovascular output.

\section{METHODS}

Patients. Thirteen children who had a diagnosis of CCHS according to standard criteria (14) and 14 control subjects (age- and sex-matched with one additional female control) participated in the study. The age of patients with CCHS was $10.9 \pm 2.3$ years (range 8-15) and of control subjects was $11.0 \pm$ 2.2 years (range $8-15$ ). Six patients with CCHS and seven control subjects were female. Patients who had CCHS and Hirschsprung's disease were excluded to avoid confounding effects from deficient neural pathways of the viscera. All subjects had tracheostomies and were ventilator dependent during sleep but not during waking; the tracheal openings were closed throughout the procedures. This study was approved by the institutional committee on human research; informed consent was obtained from each subject's guardian.

Forehead cold pressor. Each subject lay supine in the MRI scanner while a baseline recording was collected for $150 \mathrm{~s}$, and for a second acquisition period beginning with a 30 -s baseline, after which a cold $\left(3^{\circ} \mathrm{C}\right)$ deuteriumfilled bag was lowered to the subject's forehead for $120 \mathrm{~s}$. Deuterium, rather than $\mathrm{H}_{2} \mathrm{O}$, was used to minimize high signal intensity contributed to images by water. Physiologic signals including blood oxygen saturation $\left(\mathrm{SaO}_{2}\right)$, the ECG, and end-tidal $\mathrm{CO}_{2}\left(\mathrm{ETCO}_{2}\right)$ were recorded simultaneously with the fMRI signal (5); the $\mathrm{ETCO}_{2}$ and $\mathrm{SaO}_{2}$ values were obtained in a subset of 13 control subjects and six patients with CCHS, with data from the remaining subjects not collected because of technical issues.

Scanning. Data were collected using a GE 1.5 Tesla Signa MRI scanner. Masking tape across the forehead and foam pads on either side of the head were used to reduce head motion. For fMRI scans, a gradient echo echo-planar imaging $(\mathrm{EPI})$ protocol (repetition time $=6 \mathrm{~s}$, time to echo $=60 \mathrm{~ms}$, flip angle $=$ $90^{\circ}$, field of view $30 \times 30 \mathrm{~cm}$, no interslice gap, and voxel size $2.3 \times 2.3 \times 5 \mathrm{~mm}$ ) was used. The EPI protocol uses the blood oxygen level dependent (BOLD) intrinsic contrast to highlight changes in neural activity (15). For each subject, baseline and challenge series were collected. Each series consisted of 24 volumes of 20 oblique image slices collected over $144 \mathrm{~s}$ ( $24 \mathrm{~s}$ baseline/120 s challenge). Conventional spin echo T1-weighted images (repetition time $=500 \mathrm{~ms}$, time to echo $=9 \mathrm{~ms}$, field of view $=30 \times 30 \mathrm{~cm}$, no interslice gap, voxel size $1.2 \times 1.2$ $\times 5 \mathrm{~mm}$ ) were acquired at the same location and orientation to aid in anatomical identification.

Data analysis. Breathing and heart rates were derived from the physiologic signals and analyzed for changes relative to baseline during the challenge and for differences between patients with CCHS and control subjects. The principal physiologic findings were reported elsewhere (5).

The MRI data were analyzed using SPM (16) and custom software. Preprocessing of the EPI images consisted of slice timing correction, correction for possible motion, spatial normalization to the Montreal Neurological Institute template, spatial smoothing, and removal of any global effects (17). A two-step spatial normalization process was used, as described previously
$(18,19)$. The T1-weighted images were also spatially normalized, and an average of all subjects' $\mathrm{T} 1$ volumes was used for display purposes.

The preprocessed functional images were analyzed using $a$ priori defined volumes of interest (VOIs) and a whole-brain cluster analysis. VOI analysis allows for examination of responses in structures regardless of the pattern of response, e.g. effects of timing of large, transient responses of interest to understanding breathing interactions may be obscured without trend analysis. The subject-by-subject outlining of relevant areas also ensures that individual differences in structure shape and size are taken into account. In contrast, cluster analysis allows for examination of the whole brain, but the procedure is based on an a priori pattern of expected response. The response pattern for cluster analysis can be modeled, for example, with an "on" and "off" condition (stimulation or no stimulation).

VOI analysis. Fifteen structures were selected on the basis of classically suggested associations with respiratory or motor control, namely the amygdala; head of caudate; hippocampus; insula; lentiform nuclei; fastigial and dentate nuclei of the cerebellum; vermis; dorsal and ventral pons; dorsal and ventral midbrain; and dorsal, medial, and ventral medulla. Some of these areas, including the dorsal medulla and pons, are particularly affected by PHOX2B expression (20). Each VOI was drawn manually on a subject-by-subject basis, using a baseline-normalized EPI image as reference; examples have been published previously (21). Regions of primary sensory projection of the $\mathrm{V}_{3}$ trigeminal (forehead) area in the ventral posterior medial nucleus of the thalamus and somatosensory parietal cortex were also selected. Bilateral structures were assessed separately by laterality, and the insula was further separated into anterior and posterior areas.

For each VOI, the average time trend of the voxels from preprocessed images was calculated for each subject. These individual time trends were averaged for patients with CCHS and control groups and plotted with betweensubject SE bars. The subjects' time trends were analyzed for responses relative to baseline and for differences between groups using repeated measures ANOVA (22).

Cluster analysis. Cluster analysis consisted of a whole-brain assessment for responses that differed between groups. The EPI images for each subject were modeled on a voxel-by-voxel basis to an earlier determined pattern of continuous blood pressure response to the cold pressure challenge, as measured in six adults and smoothed using a moving-average filter. For baseline, the pattern was a flat line; baseline consisted of the entire baseline series and the first four scans of the challenge series. Arbitrary offsets of overall absolute image intensities between baseline and challenge series were partitioned in the model. A second-level analysis, consisting of a two-sample $t$ test of the parameter estimates in the model at each voxel (23), was performed to detect any regions where the response differed consistently between groups. Because neural responses were not expected to precisely match the model, a relatively low threshold of $p<0.01$ (minimum size 6 voxels) was used to allow detection of regions where responses that approximated the model differed between groups. The nature of the response differences within selected clusters was further examined by plotting the average group time courses of all voxels within each cluster.

\section{RESULTS}

Physiologic measures. Respiratory and cardiac rate and variability measures have been described earlier (5); briefly, respiratory rates and respiratory-related heart rate variation did not increase to the cold challenge in patients with CCHS, unlike control subjects, but low-frequency variability increases appeared in both groups. Significantly higher $\mathrm{ETCO}_{2}$ and lower $\mathrm{SaO}_{2}$ levels appeared in patients with CCHS compared with control subjects over the entire recording period, but no changes emerged across the challenge for either group (Table 1).

VOI analysis. Summary data for 23 VOIs are shown in Table 2; time trends from a subset of sites are shown in Fig. 1. Several sites showed lateralized responses in both groups (Table 2); bilateral comparisons were made for regions that showed lateralized responses, whereas regions with similar responses on the left and right side or medial structures were presented as one structure. The most common finding was an increased signal in the control group with diminished extent of responses in the CCHS group. Thus, CCHS responses tended 
Table 1. $\mathrm{ETCO}_{2}$ and $\mathrm{SaO}_{2}$ measured during baseline and during the first and second minutes of the challenge, with SE in a subset of subjects (13 control and six CCHS)

\begin{tabular}{|c|c|c|c|c|}
\hline \multirow[b]{2}{*}{ Time } & \multicolumn{2}{|c|}{$\begin{array}{c}\text { Control } \\
(N=13)\end{array}$} & \multicolumn{2}{|c|}{$\begin{array}{l}\text { CCHS } \\
(N=6)\end{array}$} \\
\hline & Value & SE & Value & SE \\
\hline \multicolumn{5}{|l|}{$\mathrm{ETCO}_{2}$} \\
\hline Baseline & 39.9 & 0.6 & 49.8 & 2.5 \\
\hline First minute & 40.2 & 0.6 & 52.0 & 1.2 \\
\hline Second minute & 40.3 & 0.6 & 51.4 & 1.4 \\
\hline \multicolumn{5}{|l|}{$\mathrm{SaO}_{2}$} \\
\hline Baseline & 98.7 & 0.2 & 94.5 & 1.0 \\
\hline First minute & 98.5 & 0.2 & 95.0 & 1.0 \\
\hline Second minute & 98.4 & 0.2 & 94.9 & 0.8 \\
\hline
\end{tabular}

There was no significant change in either measurement for either group between baseline and challenge periods. $\mathrm{ETCO}_{2}$ was significantly higher in patients with CCHS compared with control subjects $(t$ test, $p<0.05)$ throughout the recording period, and $\mathrm{SaO}_{2}$ was significantly lower throughout in patients with CCHS.

Table 2. Summary of VOI analysis

\begin{tabular}{|c|c|c|c|}
\hline Area name of VOI & $\begin{array}{l}\text { Control } \\
(N=14)\end{array}$ & $\begin{array}{c}\text { CCHS } \\
(N=13)\end{array}$ & Group \\
\hline \multicolumn{4}{|l|}{ Sensory regions } \\
\hline $\begin{array}{l}\text { Ventral parietal somatosensory } \\
\text { cortex (forehead) }\end{array}$ & - & 0 & $*$ \\
\hline Ventral posterior medial thalamus & ++ & + & $*$ \\
\hline \multicolumn{4}{|l|}{ Basal ganglia } \\
\hline Head of caudate & ++ & -+ & $*$ \\
\hline Left lentiform & ++ & +- & $*$ \\
\hline Right lentiform & ++ & + & $*$ \\
\hline \multicolumn{4}{|l|}{ Limbic regions } \\
\hline Left amygdala & + & + & \\
\hline Right amygdala & 0 & 0 & \\
\hline Left hippocampus & 0 & + & \\
\hline Right hippocampus & + & + & \\
\hline Left anterior insula & 0 & 0 & \\
\hline Right anterior insula & - & - & \\
\hline Left posterior insula & + & + & \\
\hline Right posterior insula & ++ & + & $*$ \\
\hline \multicolumn{4}{|l|}{ Brainstem regions } \\
\hline Dorsal midbrain & ++ & + & $*$ \\
\hline Ventral midbrain & ++ & + & $*$ \\
\hline Dorsal pons & + & + & \\
\hline Ventral pons & + & + & \\
\hline Dorsal medulla & 0 & 0 & \\
\hline Medial medulla & - & + & $*$ \\
\hline Ventral medulla & - & + & $*$ \\
\hline \multicolumn{4}{|l|}{ Cerebellar regions } \\
\hline Dentate nucleus & ++ & + & * \\
\hline Fastigial nucleus & ++ & +- & $*$ \\
\hline Culmen of the vermis & + & 0 & $*$ \\
\hline
\end{tabular}

Significance was tested using repeated measures ANOVA $(p<0.05)$. Significant signal increase $(+)$ or decrease $(-)$ or no significant difference $(0)$ is indicated for each group, relative to baseline, where baseline is the combined baseline series and initial $30 \mathrm{~s}$ of the challenge series. Group differences are indicated by an asterisk (*). Where both groups increased and a group effect was noted, the group with the greater extent of signal change is indicated by " ++ ." Where values from a group increased above baseline and then decreased, the symbol "+-" is used; for a decrease followed by an increase, " -+ " is used.

to be less pronounced, more transient, absent, or a modest change in the opposite direction compared with control subjects, as indicated by the data from the head of caudate, lentiform nuclei, cerebellar dentate and fastigial nuclei and vermis, and dorsal and ventral midbrain in Fig. 1. The region of forehead representation in the primary sensory cortex showed an initial decline in both groups but a return to baseline in CCHS patients, with a sustained fall in control subjects. The ventral posterior medial nucleus of the thalamus, the primary somatosensory nucleus for the head, showed a signal increase in both groups, but the increase was larger in control subjects over patients with CCHS. In contrast to the control pattern, the medial and ventral medulla showed a larger transient increase in patients with CCHS, lasting $\sim 60 \mathrm{~s}$. The dorsal and ventral pons showed no group differences. Of the VOIs not in Fig. 1, the left amygdala showed comparable increases in both groups, but the right side showed no change in either group. The hippocampus and posterior insula showed lateralized responses. The left anterior insula remained at baseline levels in both groups, and the right anterior portion showed a comparable decline in patients with CCHS and control subjects. No change occurred in either group in the dorsal medulla.

The lentiform nuclei showed a transient response, with the control group having higher signals during the first minute. The dentate and fastigial nuclei patterns were notable in that the group differences developed principally in the last minute of the challenge.

Cluster analysis. Table 3 shows all clusters of significant group difference, and Fig. 2 illustrates selected clusters overlaid on an average of all subjects' anatomical T1-weighted images. Figure 3 shows time trend patterns of signal changes from selected clusters.

The cluster analysis principally showed larger and more sustained signal responses in control subjects than in patients with CCHS, as with the VOI analysis. Cortical regions where control subjects demonstrated greater responses than patients with CCHS included the superior surface of the right temporal lobe (Fig. 2 C5-C6), and the mid- and posterior cingulate (B3-B5, C4-C6). Cortical regions where control responses declined while CCHS signals remained unchanged emerged in the frontal cortex extending to the anterior cingulate (B3-B5, $\mathrm{C} 7)$, the superior frontal cortex (C7-C8), and the left prefrontal cortex (A6-A7, C7). The time courses of the clusters of group difference in cortical regions showed differences throughout the challenge period (Fig. 3). The right posterior insula showed increased signals in control subjects over patients with CCHS (A4-A5), together with mid portions of the hippocampal formation (B7, C5), dorsal thalamus (B2, C5), and dorsal hypothalamus (B2, C5). Signals in the dorsal hypothalamus and insula increased early in the response and later declined in control subjects but not patients with CCHS (Fig. 3). In the cerebellum, the control group showed several regions of greater signal over the CCHS group, including the vermis (Fig. 2, A1, B3-B4), dentate nucleus (A2, B2), and quadrangular lobule of the cerebellar cortex (B3, C1-C3). The time course of the cerebellar cortex cluster differed between groups only in the second minute of the challenge, with similar signal increases in the first minute occurring in both groups (Fig. 3).

\section{DISCUSSION}

Sensory, motor, and integration areas showed deficits in patients with CCHS to the cold pressor challenge. Diminished 
Table 3. Clusters of voxels with a significant $(p<0.01)$ difference in response between groups $(14$ control and 13 CCHS subjects), where the response is modeled as a typical pattern of blood pressure increase

\begin{tabular}{|c|c|c|c|c|}
\hline Area name of cluster & $\begin{array}{c}\text { MNI } \\
\text { co-ordinates }\end{array}$ & $\begin{array}{l}\text { Significance } \\
\text { (t-statistic) }\end{array}$ & $\begin{array}{l}\text { Cluster size } \\
\text { (voxels) }\end{array}$ & $\begin{array}{c}\text { Control } \\
\text { vs. CCHS }\end{array}$ \\
\hline \multicolumn{5}{|l|}{ Cortical regions } \\
\hline Temporal Lobe Superior cortex & 5804 & 4.4 & 439 & $>$ \\
\hline \multicolumn{5}{|l|}{ Brodmann 48 Right } \\
\hline \multicolumn{5}{|l|}{ Brodmann 38 Right } \\
\hline \multicolumn{5}{|l|}{ Brodmann 22 Right } \\
\hline \multicolumn{5}{|l|}{ Brodmann 21 Right } \\
\hline Brodmann 22 Left & $-66-66$ & 2.7 & 11 & $>$ \\
\hline Mid/Posterior Cingulate & $-2-2240$ & 3.4 & 273 & $>$ \\
\hline \multicolumn{5}{|l|}{ Brodmann 23} \\
\hline Mid Cingulate & 6244 & 2.9 & 49 & $>$ \\
\hline \multicolumn{5}{|l|}{ Brodmann 24} \\
\hline Mid Cingulate & 01232 & 2.5 & 6 & $>$ \\
\hline \multicolumn{5}{|l|}{ Brodmann 24} \\
\hline Brodmann 17, 18 Left & $-12-704$ & 2.9 & 134 & $>$ \\
\hline Brodmann 17, 18 Right & $14-728$ & 2.8 & 99 & $>$ \\
\hline Prefrontal Cortex Left & -306022 & 3.2 & 193 & $<$ \\
\hline \multicolumn{5}{|l|}{ Brodmann 46 Left } \\
\hline \multicolumn{5}{|l|}{ Brodmann 10} \\
\hline Frontal Cortex/Anterior & 104448 & 3.1 & 206 & $<$ \\
\hline \multicolumn{5}{|l|}{ Cingulate Right } \\
\hline \multicolumn{5}{|l|}{ Brodmann 9} \\
\hline \multicolumn{5}{|l|}{ Brodmann 32} \\
\hline \multicolumn{5}{|l|}{ Brodmann 8} \\
\hline Anterior Cingulate Right & 164820 & 3 & 237 & $<$ \\
\hline \multicolumn{5}{|l|}{ Brodmann 32} \\
\hline Brodmann 46 Right & & & & \\
\hline Brodmann 10 & & & & \\
\hline Superior Frontal Cortex Left & -163456 & 2.8 & 18 & $<$ \\
\hline Brodmann 8 & & & & \\
\hline Brodmann 9 & & & & \\
\hline Deep Frontal Cortex Left & -163812 & 2.7 & 58 & $<$ \\
\hline Brodmann 32 & & & & \\
\hline Superior Frontal Cortex Left & -264444 & 2.6 & 27 & $<$ \\
\hline Brodmann 9 & & & & \\
\hline Deep Frontal Cortex/Anterior & -44430 & 2.6 & 44 & $<$ \\
\hline Cingulate & & & & \\
\hline Brodmann 32 & & & & \\
\hline Basal ganglia/limbic/thalamic regio & & & & \\
\hline Insula Posterior Right & $44-22-2$ & 4.3 & 530 & $>$ \\
\hline Mid hippocampus & & & & \\
\hline Brodmann 20 Right & & & & \\
\hline Brodmann 48 Right & & & & \\
\hline Brodmann 37 Right & & & & \\
\hline Insula Left & $-34-3214$ & 4.2 & 353 & $>$ \\
\hline Mid hippocampus & & & & \\
\hline Brodmann 48 Left & & & & \\
\hline Brodmann 20 Left & & & & \\
\hline Brodmann 41 Left & & & & \\
\hline Dorsal hypothalamus & $-8-10-4$ & 3.3 & 19 & $>$ \\
\hline Dorsal Thalamus & $-10-1016$ & 2.6 & 6 & $>$ \\
\hline Head of Hippocampus Left & $18-428$ & 3.6 & 15 & $>$ \\
\hline Brodmann 27 Right & & & & \\
\hline Brodmann 37 Right & & & & \\
\hline Head of Hippocampus Left & $-22-460$ & 3.2 & 56 & $>$ \\
\hline Brodmann 37 Left & & & & \\
\hline Cerebellar regions & & & & \\
\hline Quadrangular Lobule & $-18-60-22$ & 3.7 & 1210 & $>$ \\
\hline Dentate & & & & \\
\hline Brodmann 37 & & & & \\
\hline Brodmann 19 & & & & \\
\hline Brodmann 18 & & & & \\
\hline Vermis & $0-62-40$ & 2.8 & 31 & $>$ \\
\hline
\end{tabular}




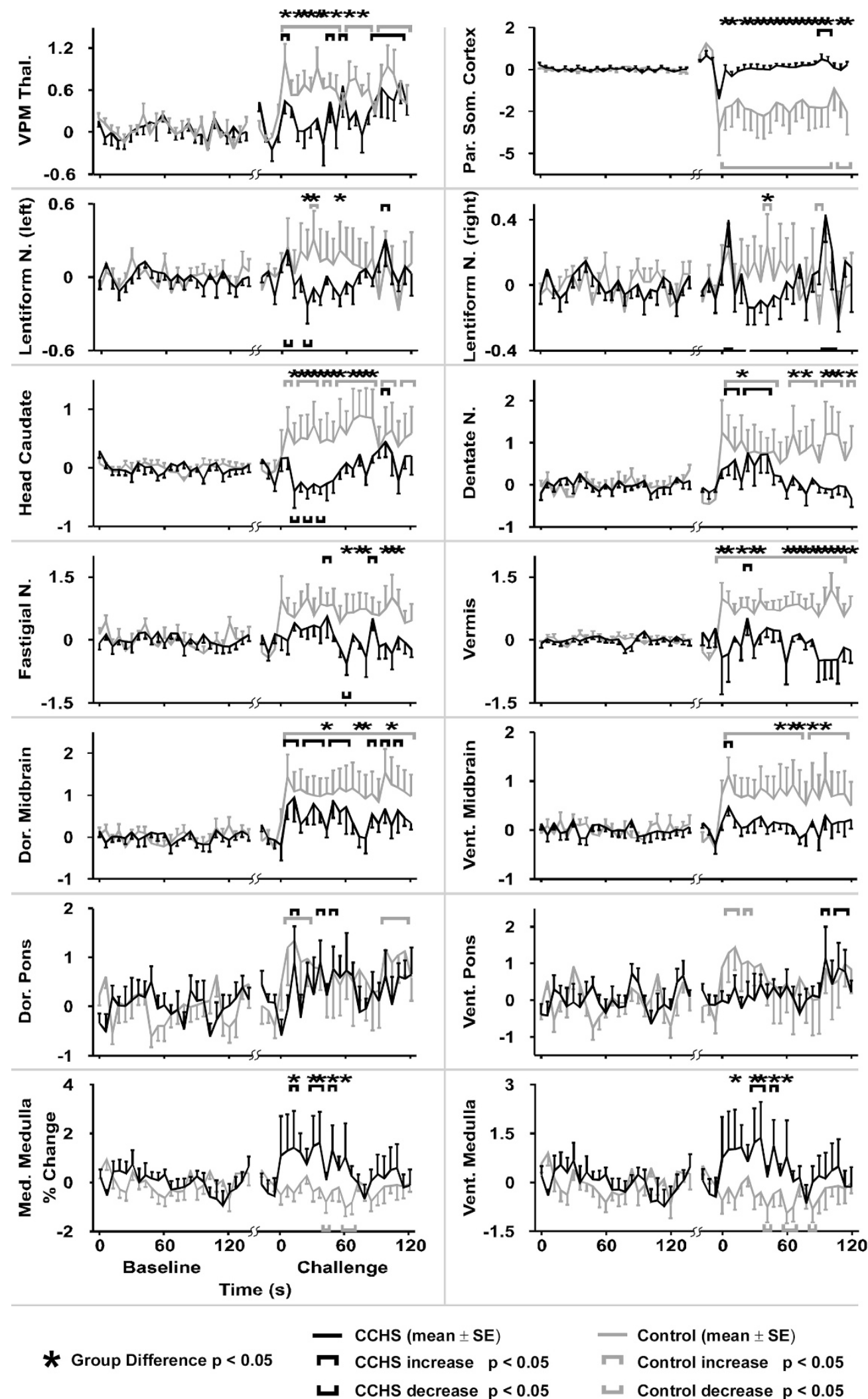

Figure 1. Average time trends of 14 VOIs for CCHS and control groups, with SE bars. Time points of significant response (increase or decrease) relative to baseline for each group are indicated, as well as time points of significant group difference (repeated measures ANOVA $p<0.05$ ). Baseline is defined as the combined baseline series and initial $30 \mathrm{~s}$ of the challenge series. VPM Thal, ventral posterior medial thalamus; Par. Som. Cortex, parietal somatosensory cortex (forehead).

cardiac variability and breathing responses emerged in the patient group, and, whereas control subjects showed significant responses within discrete sites in the cerebellum, basal ganglia, and cortical regions, the most common deficit found in patients with CCHS was reduced change in signal within these areas. However, larger signal increases were found in medial medul- 

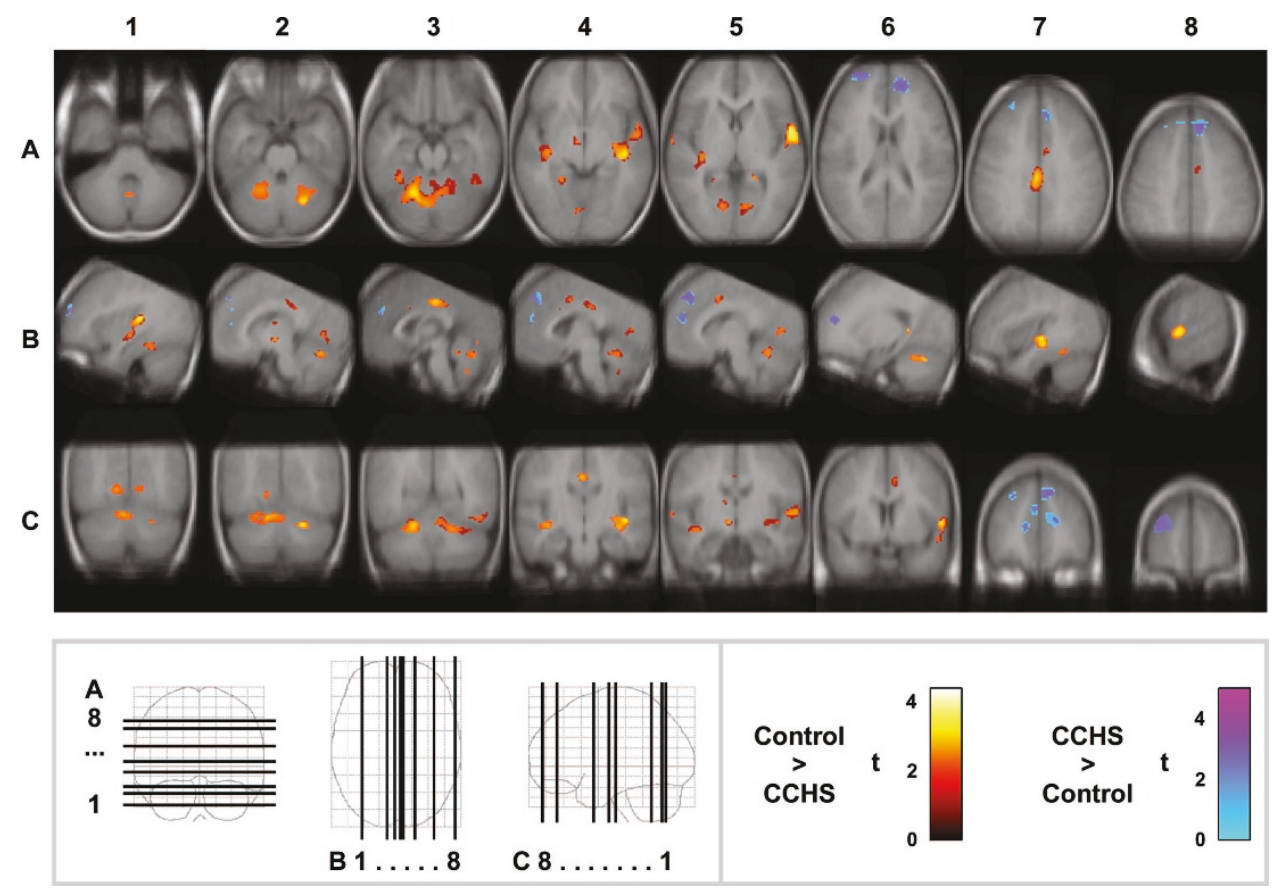

Figure 2. Clusters of group difference in response, as determined by modeling image series time course to a typical pattern of blood pressure increase, color-coded according to statistical significance ( $t$ value) and overlaid onto the average of all 27 subjects' anatomical T1 images. Regions of control $>$ CCHS are in warm (yellow-red) colors and regions of CCHS $>$ control are in cool (blue-green) colors, coded according to significance level (key bottom right). Locations of axial $(A)$, sagittal $(B)$, and coronal $(C)$ views are indicated in sketch at bottom left. Note that the "warm" $v s$ "cool" color coding refers to the group difference direction, not difference in extent of response, i.e. the blue "CCHS > control" colors in the cortical regions indicate a response decline in control cases but not necessarily greater extent of response in patients with CCHS compared with control subjects (as illustrated in Fig. 3).

lary inhibitory areas and the ventral medulla of patients with CCHS. A region expected to be affected by mutations in PHOX2B transcription, the dorsal medulla, showed little response in patients with CCHS or control subjects. We speculate that the diminished and altered physiologic and neural responsiveness in CCHS results from enhanced action of medullary inhibitory areas, from aberrant cerebellar influences on projection sites, particularly in the frontal cortex and indirect to basal ganglia, and from a generalized unresponsiveness in neural sites as a result of deficient cardiovascular reactivity. PHOX2B mutations, because of their effect on autonomic processes, may play a significant role in the reduced reactivity.

Timing. The cold application normally elicits an increase in breathing rate and enhances rapid, respiratory-related heart rate variation. Both characteristics were missing in patients with CCHS, although slower $(<0.1 \mathrm{~Hz})$ heart rate variation changes were similar in the two groups. Respiratory influences on heart rate were already diminished during baseline conditions in the patient group (5); a failure to increase rapid heart rate variability changes to hypercapnia in patients with CCHS has been reported (17). Cerebellar structures have been implicated in other rapid-physiologic-adjustment deficits, including somatic movements (24) and cognitive switching tasks, such as those in autistic disorders (25), a syndrome associated with reduced Purkinje cell size (26) and impaired cerebellar-cerebral projections (27). Cognitive disorders of an autistic nature do not always accompany CCHS, although patients with CCHS do show below-average motor hand coordination performance (28). The aberrant cerebellar responses in CCHS appeared in dorsal anterior and deep nuclei structures, in addition to vermal areas usually affected in autism (29). The diminished rapid heart rate changes to breathing suggest that the loss of rapid coordination of physiologic functions in CCHS extends to autonomic aspects.

PHOX2B targets. An unexpected finding was the absence, in either group, of responses from the dorsal medulla, including the NTS or the dorsal pons, containing the locus coeruleus. The absence of a response in dorsal medullary areas probably stems from the nature of the cold pressor stimulation, which was not a chemoreceptor challenge, and apparently did not recruit NTS neural action in a major way in either control subjects or patients with CCHS. Both the NTS and the locus coeruleus would be expected to be affected by mutations of PHOX2B $(20,30)$. Mutations would likely also affect autonomic ganglia associated with the 7th, 9th, and 10th cranial nerves (20); the actions of these peripheral structures, however, could not be assessed in this study. Localized responses within the nucleus ambiguus, the primary effector nucleus for rapid cardiac rate changes (31), and a branchial arch motor nucleus likely to be affected by PHOX2B developmental issues, also could not be examined with the resolution of the current MRI procedures. It is likely that defects in sympathetic ganglia resulting from PHOX2B mutations contribute to aberrant sympathetic patterns found in CCHS. The loss of cerebrovascular reactivity, found earlier by assessing global magnetic resonance signal changes over the brain (32), could also stem from such mutations. 

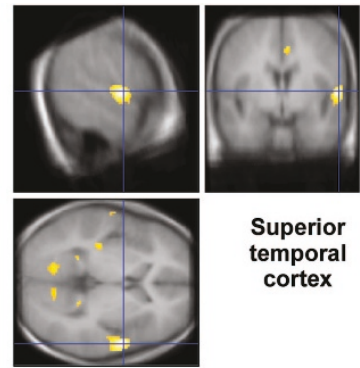

Superior temporal cortex

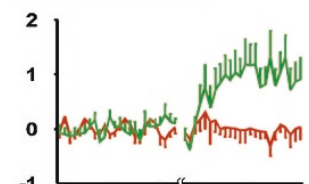

$-1$
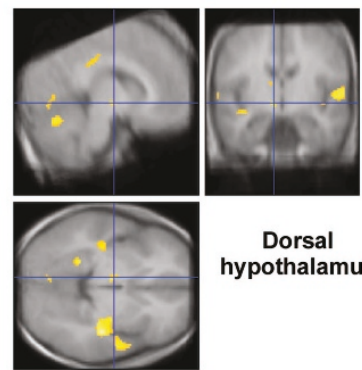

Dorsal hypothalamus
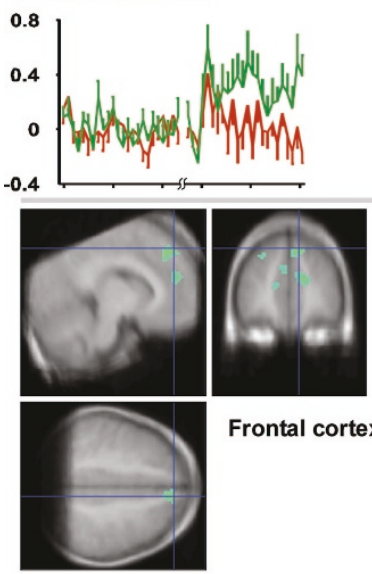

Frontal cortex

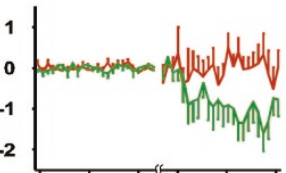

- CCHS (mean $\pm \mathrm{SE}$ )
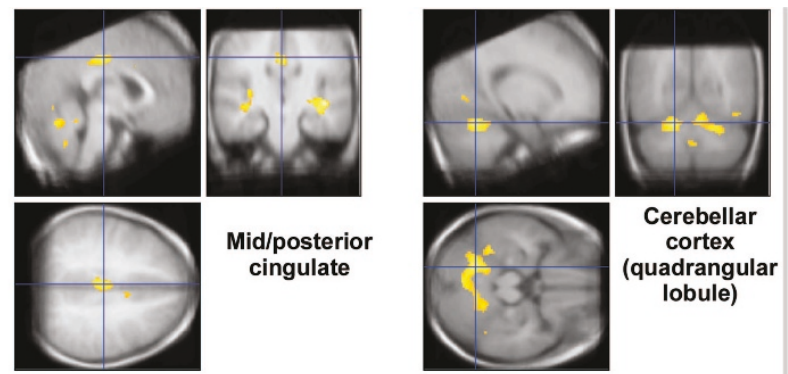

Control

Cे
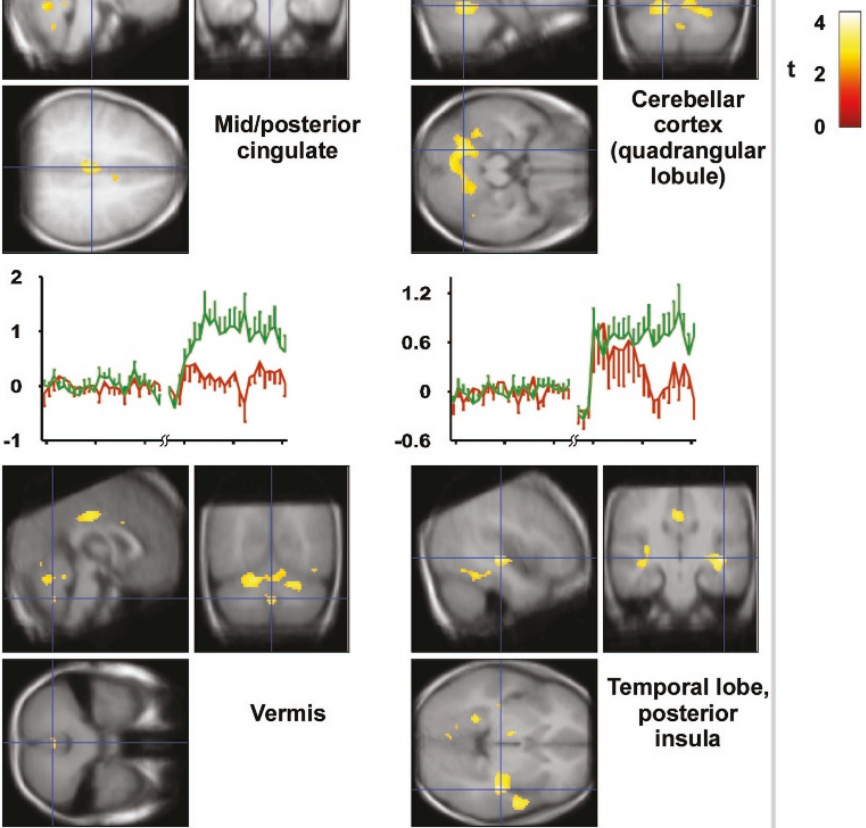

Vermis
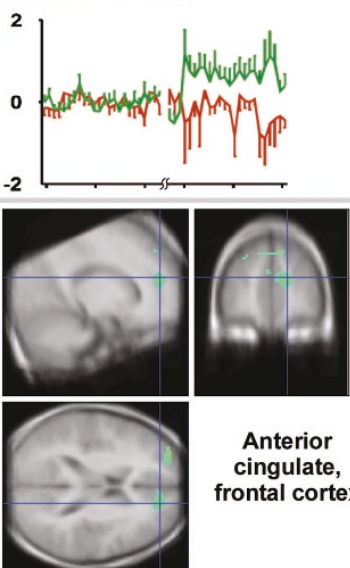

\section{Anterior} cingulate, frontal cortex
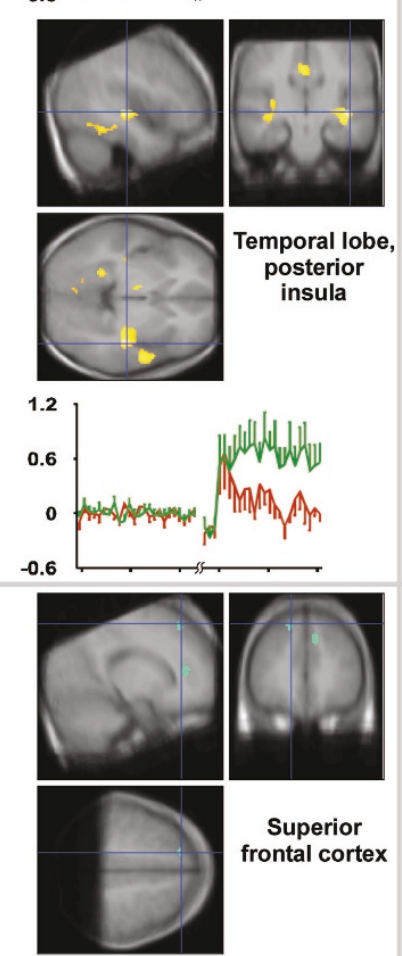

Control

cCHs

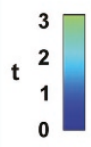

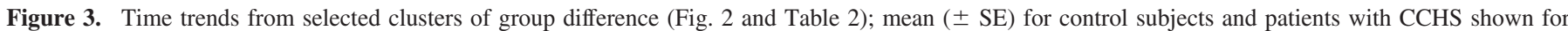
baseline and challenge series. Cluster overlays follow the same conventions as Fig. 2.

Cerebellum. Cerebellar Purkinje neurons normally inhibit deep nuclei; regions within the cerebellar cortex, dentate, and fastigial deep nuclei showed higher signals in control subjects, presumably representing enhanced Purkinje influences on the deep nuclei that project to more rostral sites. Excitation of the fastigial nucleus augments breathing, and lesions reduce the ventilatory response to hypercapnia and hypoxia (33-35). Cardiovascular functions are also modified by fastigial action $(36,37)$. The impaired recruitment of the fastigial nucleus to the cold pressor challenge may contribute to the failure to respond appropriately with augmented breathing and respiratoryrelated heart rate variation.

The dentate nucleus also showed signal deficits in patients with CCHS late in the challenge. The dentate nucleus, once considered a motor-only-related nucleus, contains a nonmotor portion that projects to thalamic and prefrontal and dorsal parietal cortex regions and apparently serves cognitive, decision-making, or visual-spatial functions (38). We could not 
differentiate motor from nonmotor portions of the dentate nucleus with the resolution offered by the scanner. The normal interaction of cerebellar nuclei with basal ganglia, frontal motor, and somatosensory parietal cortex likely results in the enhanced caudate and lentiform signals in control cases; some of the timing issues in CCHS may be related to cerebellar/basal ganglia deficits.

The deficiencies in cerebellar responses may partially result from repetitive exposure to hypoxia, a consequence of ineffective ventilation during sleep or relaxation periods in these children. Climbing fibers from the inferior olive are especially sensitive to hypoxia, with resultant damage to Purkinje cells (39), which normally inhibit deep nuclei (40). The release of inhibition to deep cerebellar nuclei, the major output from the cerebellum, can exert considerable influences on more rostral projection sites.

Cingulate and insula. The cingulate cortex in patients with CCHS showed diminished responses and was of particular interest. Unlike the response to expiratory loading, in which nearly the entire structure showed group differences (21), only a defined region within the mid-to-caudal cingulate showed a lower response in CCHS patients. The affected cingulate region borders an area previously identified with sympathetic nervous system activation (41). The patients with CCHS did not differ markedly in response to the cold pressor challenge on slow variation in heart rate, although more rapid, presumably parasympathetically related variation was substantially diminished. The right insula deficits may act in concert with the cingulate cortex to mediate aberrant autonomic responses; insular structures show significant lateralized effects on autonomic outflow, with the left insula principally involved in parasympathetic control and the right insula in sympathetic action $(42,43)$. Other cardiovascular syndromes with substantial loss of respiratory-related variation, such as adult heart failure (44), also show considerable right insular damage (45), and adult patients with obstructive sleep apnea show aberrant right insular responses to cold pressor challenges (19). Lateralization of brain responses to autonomic challenges in adult control subjects has been noted earlier $(46,47)$ and occurs in multiple limbic structures. The collective findings emphasize that autonomic control patterns may be regulated by one side of the brain over the other, an issue of theoretical importance and of practical significance in conditions of early neural damage.

Enhanced responses in $\boldsymbol{C C H S}$. The patients with CCHS did not show uniform patterns of reduced signal response over control subjects. Both the medial and the ventral medulla showed enhanced responses in patients with CCHS over virtually no change in control subjects. The motor suppression areas of the medial medulla (48-50) may be exerting inhibitory or dysfacilitatory control over a number of neural sites, contributing to the muted or absence of responses in multiple sites and leading to reduced respiratory and cardiovascular action. The medial medullary areas serve important roles in maintaining motor tone relative to blood pressure levels and interact closely with vestibular and cerebellar projections in that role (51). Influences from dorsolateral pontine regions on the medial medulla have been suggested as regulating staterelated medial medullary atonia (49); however, little change was found in dorsal pontine areas between the two groups here. We speculate that the medial medullary responses likely arose from cerebellar-medial medullary interactions (52-55) in these waking studies. The influences from medial and ventral medullary areas may assist in mediating diminished CCHS responses through motor control areas at multiple levels of the neuraxis, including the basal ganglia (left and right lentiform nuclei) and midbrain sites.

Muted responses in CCHS. The greatest proportion of regional differences between patients with CCHS and control subjects developed from muted, shorter term, or absent signal changes in patients with CCHS in neural regions where signals in control subjects rose. Several processes may contribute to the muted responses, among which is the possibility of reduced overall cerebral reactivity in patients with CCHS; such a possibility stems from the demonstration of reduced global BOLD signal to ventilatory challenges in the syndrome (32). The enhanced signals in unique sites within patients with CCHS, however, suggest that the reduced responsiveness does not result entirely from reduced cerebral reactivity. The frontal cortex time-trend plots and the demonstrated projections to those sites suggest that components of the responses derived from influences of more active cerebellar deep nuclei in control subjects, resulting in lowered signals, while values in patients with CCHS remained the same or rose slightly. The primary somatosensory cortex showed an immediate response in the same direction and extent as the control group but no sustained response. Thus, an initial sensory cortical response seems to be comparable in the two groups, but influences from cerebellar and other sources that mediate the integrative sensorimotor aspects to cold may affect the late cortical pattern. The absence or diminished late response in certain regions of patients with CCHS may reflect enhanced responses of other sites, particularly medullary inhibitory areas described earlier.

Limitations. It was not possible to separate neural abnormalities that resulted from potential hypoxic damage from those that were caused by preexisting developmental deficiencies. Recent progress in MRI technologies may offer the possibility of such determination.

The 6-s period required to acquire each functional image volume limited the ability to measure very rapidly changing neural patterns. Thus, patterns of neural responses related to the diminution of very fast heart rate responses to breathing or other sudden physiologic changes were restricted. Such patterns could be examined by reducing the field of view and by implementing recently developed faster scanning procedures; the objective of this study was to provide a survey of potential changes over as large a brain area as possible.

The cold application has the potential to modify the global cerebral circulation with resulting global effects in the BOLD signal. We addressed this issue by removing all global components from the data (17), leaving the regional responses to the stimulation.

The findings represent data from a restricted sample, namely patients who were ventilator dependent only during sleep. Neural responses may differ from patients who are continu- 
ously ventilator dependent and thus might exhibit even more extensive dysfunction. However, examination of such cases was precluded by logistic issues of scanner safety.

\section{SUMMARY}

Localized areas of the brain, principally involving cerebellar, medullary, basal ganglia, frontal, insular, temporal, and cingulate cortex regions, showed different response patterns to facial cold stimulation, a nonchemoreceptor challenge, in patients with CCHS compared with control subjects. The aberrant responses included muted or no change in signals compared with significant responses in control subjects or an increase in signals where none were normally present and may underlie the failure to elevate respiratory rate and enhance respiratoryrelated heart rate variation to the manipulation. Although PHOX2B mutations likely contribute to multiple autonomic deficiencies in CCHS, a structure expected to be affected by such mutations showed little change in response to the cold pressor application. Neural responses to the cold pressor challenge have the potential to reveal deficiencies in other processes that may not be targeted directly by the mutation. Among the affected sites, primary sensory-mediating structures in the thalamus and somatosensory cortex showed reduced signal changes in patients with CCHS. Some of the reduced signal responsiveness may have resulted from diminished cerebral reactivity in patients with CCHS; other contributions are likely to have developed from medial medullary inhibitory or dysfacilitatory influences or from reduced control by cerebellar projections. The increased responses in medullary sites argue against a generalized loss of cerebral reactivity and suggest a selective active suppression of aspects of breathing and rapidly changing integrative mechanisms.

Acknowledgments. We thank Dr. Munawar Saeed, Rebecca Harper, and Amy Kim for assistance with data collection and Drs. Rajesh Kumar and Luke Henderson for help with manuscript editing.

\section{REFERENCES}

1. Haddad GG, Mazza NM, Defendini R, Blanc WA, Driscoll JM, Epstein MA, Epstein RA, Mellins RB 1978 Congenital failure of automatic control of ventilation, gastrointestinal motility and heart rate. Medicine (Baltimore) 57:517-526

2. Paton JY, Swaminathan S, Sargent CW, Keens TG 1989 Hypoxic and hypercapnic ventilatory responses in awake children with congenital central hypoventilation syndrome. Am Rev Respir Dis 140:368-372

3. Oren J, Kelly DH, Shannon DC 1987 Long-term follow-up of children with congenital central hypoventilation syndrome. Pediatrics 80:375-380

4. Commare MC, Francois B, Estournet B, Barois A 1993 Ondine's curse: a discussion of five cases. Neuropediatrics 24:313-318

5. Kim AH, Macey PM, Woo MA, Yu PL, Keen TG, Gozal D, Harper RM 2002 Cardiac responses to pressor challenges in Congenital Central Hypoventilation Syndrome. Somnologie 6:109-115

6. Woo MS, Woo MA, Gozal D, Jansen MT, Keens TG, Harper RM 1992 Heart rate variability in congenital central hypoventilation syndrome. Pediatr Res 31:291-296

7. Weese-Mayer DE, Berry-Kravis EM, Zhou L, Maher BS, Silvestri JM, Curran ME, Marazita ML 2003 Idiopathic congenital central hypoventilation syndrome: analysis of genes pertinent to early autonomic nervous system embryologic development and identification of mutations in PHOX2b. Am J Med Genet 123A:267-278

8. Amiel J, Laudier B, Attie-Bitach T, Trang H, de Pontual L, Gener B, Trochet D, Etchevers H, Ray P, Simonneau M, Vekemans M, Munnich A, Gaultier C, Lyonnet S 2003 Polyalanine expansion and frameshift mutations of the paired-like homeobox gene PHOX2B in congenital central hypoventilation syndrome. Nat Genet 33:459461
9. Gozal D, Marcus CL, Shoseyov D, Keens TG 1993 Peripheral chemoreceptor function in children with the congenital central hypoventilation syndrome. J Appl Physiol 74:379-387

10. Koulchitsky SV, Levkovets VS, Tchitchkan DN, Soltanov VV, Kulchitsky VA 1999 Role of the solitary tract nucleus and caudal ventrolateral medulla in temperature responses in endotoxemic rats. Life Sci 64:37-43

11. Paton JY, Swaminathan S, Sargent CW, Hawksworth A, Keens TG 1993 Ventilatory response to exercise in children with congenital central hypoventilation syndrome. Am Rev Respir Dis 147:1185-1191

12. Shea SA, Andres LP, Shannon DC, Banzett RB 1993 Ventilatory responses to exercise in humans lacking ventilatory chemosensitivity. J Physiol 468:623-640

13. Spengler CM, Banzett RB, Systrom DM, Shannon DC, Shea SA 1998 Respiratory sensations during heavy exercise in subjects without respiratory chemosensitivity. Respir Physiol 114:65-74

14. American Thoracic Society 1999 Idiopathic congenital central hypoventilation syndrome: diagnosis and management. Am J Respir Crit Care Med 160:368-373

15. Kwong KK, Belliveau JW, Chesler DA, Goldberg IE, Weisskoff RM, Poncelet BP, Kennedy DN, Hoppel BE, Cohen MS, Turner R Cheng HM, Brady TJ, Rosen BR 1992 Dynamic magnetic resonance imaging of human brain activity during primary sensory stimulation. Proc Natl Acad Sci USA 89:5675-5679

16. Friston KJ, Holmes AP, Poline JB, Grasby PJ, Williams SC, Frackowiak RS, Turner R 1995 Analysis of fMRI time-series revisited. Neuroimage 2:45-53

17. Macey PM, Macey KE, Kumar R, Harper RM 2004 A method for removal of global effects from fMRI time series. Neuroimage 22:360-366

18. Macey PM, Macey KE, Henderson LA, Alger JR, Frysinger RC, Woo MA, Yan-Go F, Harper RM 2003 Functional magnetic resonance imaging responses to expiratory loading in obstructive sleep apnea. Respir Physiol Neurobiol 138:275-290

19. Harper RM, Macey PM, Henderson LA, Woo MA, Macey KE, Frysinger RC, Alger JR, Nguyen KP, Yan-Go FL 2003 fMRI responses to cold pressor challenges in control and obstructive sleep apnea subjects. J Appl Physiol 94:1583-1595

20. Dauger S, Pattyn A, Lofaso F, Gaultier C, Goridis C, Gallego J, Brunet JF 2003 Phox $2 \mathrm{~b}$ controls the development of peripheral chemoreceptors and afferent visceral pathways. Development 130:6635-6642

21. Macey KE, Macey PM, Woo MA, Harper RK, Alger JR, Keen TG, Harper RM 2004 fMRI signal changes in response to forced expiratory loading in congenital central hypoventilation syndrome. J Appl Physiol 97:1897-1907

22. Littell RC, Milliken GA, Stroup WW, Wolfinger RD 1996 SAS System for Mixed Models. SAS Institute, Cary, NC

23. Holmes AP, Friston KJ 1998 Generalisability, random effects and population inference. Neuroimage 7:S754

24. Ito M 2002 Historical review of the significance of the cerebellum and the role of Purkinje cells in motor learning. Ann NY Acad Sci 978:273-288

25. Lincoln A, Lai Z, Jones W 2002 Shifting attention and joint attention dissociation in Williams syndrome: implications for the cerebellum and social deficits in autism. Neurocase 8:226-232

26. Fatemi SH, Halt AR, Realmuto G, Earle J, Kist DA, Thuras P, Merz A 2002 Purkinje cell size is reduced in cerebellum of patients with autism. Cell Mol Neurobiol 22:171-175

27. Skoyles JR 2002 Is autism due to cerebral-cerebellum disconnection? Med Hypotheses 58:332-336

28. Silvestri JM, Weese-Mayer DE, Nelson MN 1992 Neuropsychologic abnormalities in children with congenital central hypoventilation syndrome. J Pediatr 120:388-393

29. Piven J, Nehme E, Simon J, Barta P, Pearlson G, Folstein SE 1992 Magnetic resonance imaging in autism: measurement of the cerebellum, pons, and fourth ventricle. Biol Psychiatry 31:491-504

30. Grillet N, Dubreuil V, Dufour HD, Brunet JF 2003 Dynamic expression of RGS4 in the developing nervous system and regulation by the neural type-specific transcription factor Phox2b. J Neurosci 23:10613-10621

31. Hopkins DA, Armour JA 1982 Medullary cells of origin of physiologically identified cardiac nerves in the dog. Brain Res Bull 8:359-365

32. Macey PM, Alger JR, Kumar R, Macey KE, Woo MA, Harper RM 2003 Global BOLD MRI changes to ventilatory challenges in congenital central hypoventilation syndrome. Respir Physiol Neurobiol 139:41-50

33. Xu F, Frazier DT 1997 Respiratory-related neurons of the fastigial nucleus in response to chemical and mechanical challenges. J Appl Physiol 82:1177-1184

34. Xu F, Frazier DT 2002 Role of the cerebellar deep nuclei in respiratory modulation. Cerebellum 1:35-40

35. Bassal M, Bianchi AL 1982 Inspiratory onset or termination induced by electrical stimulation of the brain. Respir Physiol 50:23-40

36. Lutherer LO, Williams JL, Everse SJ 1989 Neurons of the rostral fastigial nucleus are responsive to cardiovascular and respiratory challenges. J Auton Nerv Syst 27:101111

37. Lutherer LO, Lutherer BC, Dormer KJ, Janssen HF, Barnes CD 1983 Bilateral lesions of the fastigial nucleus prevent the recovery of blood pressure following hypotension induced by hemorrhage or administration of endotoxin. Brain Res 269:251-257

38. Dum RP, Li C, Strick PL 2002 Motor and nonmotor domains in the monkey dentate. Ann NY Acad Sci 978:289-301

39. Welsh JP, Yuen G, Placantonakis DG, Vu TQ, Haiss F, O'Hearn E, Molliver ME, Aicher SA 2002 Why do Purkinje cells die so easily after global brain ischemia? Aldolase C, EAAT4, and the cerebellar contribution to posthypoxic myoclonus. Adv Neurol 89:331-359

40. Ohtsuka K 1988 Inhibitory action of Purkinje cells in the posterior vermis on fastigio-prepositus circuit of the cat. Brain Res 455:153-156

41. Critchley HD, Corfield DR, Chandler MP, Mathias CJ, Dolan RJ 2000 Cerebral correlates of autonomic cardiovascular arousal: a functional neuroimaging investigation in humans. J Physiol 523(suppl):259-270 
42. Oppenheimer SM, Gelb A, Girvin JP, Hachinski VC 1992 Cardiovascular effects of human insular cortex stimulation. Neurology 42:1727-1732

43. Oppenheimer SM, Kedem G, Martin WM 1996 Left-insular cortex lesions perturb cardiac autonomic tone in humans. Clin Auton Res 6:131-140

44. Woo MA, Stevenson WG, Moser DK, Trelease RB, Harper RM 1992 Patterns of beat-to-beat heart rate variability in advanced heart failure. Am Heart J 123:704-710

45. Woo MA, Macey PM, Fonarow GC, Hamilton MA, Harper RM 2003 Regional brain gray matter loss in heart failure. J Appl Physiol 95:677-684

46. King AB, Menon RS, Hachinski V, Cechetto DF 1999 Human forebrain activation by visceral stimuli. J Comp Neurol 413:572-582

47. Harper RM, Bandler R, Spriggs D, Alger JR 2000 Lateralized and widespread brain activation during transient blood pressure elevation revealed by magnetic resonance imaging. J Comp Neurol 417:195-204

48. Hajnik T, Lai YY, Siegel JM 2000 Atonia-related regions in the rodent pons and medulla. J Neurophysiol 84:1942-1948

49. Lai YY, Siegel JM 1988 Medullary regions mediating atonia. J Neurosci 8:4790-4796
50. Magoun H, Rhines R 1946 An inhibitory mechanism in the bulbar reticular formation. J Neurophysiol 9:165-171

51. Mori RL, Bergsman AE, Holmes MJ, Yates BJ 2001 Role of the medial medullary reticular formation in relaying vestibular signals to the diaphragm and abdominal muscles. Brain Res 902:82-91

52. Homma Y, Nonaka S, Matsuyama K, Mori S 1995 Fastigiofugal projection to the brainstem nuclei in the cat: an anterograde PHA-L tracing study. Neurosci Res 23:89-102

53. Morris R 1987 Responses of neurones in the brainstem raphe nuclei to stimulation of the cerebellar fastigial nuclei in the cat. Neurosci Lett 74:19-24

54. Takagi H, Senba E, Shiosaka S, Sakanaka M, Inagaki S, Takatsuki K, Tohyama M 1981 Ascending and cerebellar non-serotonergic projections from the nucleus raphe magnus of the rat. Brain Res 206:161-165

55. Zimny R, Grottel K, Jakielska D 1988 Afferent fiber connections from the raphe nuclei to the cerebellar paramedian lobule. A histochemical study in the rabbit utilizing horseradish peroxidase as a retrograde marker. J Hirnforsch 29:21-35 